\title{
Formação continuada em Educação Ambiental: uma proposta em movimento
}

\author{
Continuing education in Environmental Education: \\ an action in movement
}

\author{
Raquel Fabiane Mafra ORSI ${ }^{1}$ \\ Antonio Fernando Silveira GUERRA ${ }^{2}$
}

\begin{abstract}
Resumo
$\mathrm{O}$ artigo apresenta um estudo desenvolvido a partir da experiência vivida nas formações continuadas de professores da Gerência de Educação de Itajaí-SC. O objetivo foi refletir sobre os elementos essenciais na formaçáo continuada que ampliem a inserção da educaçáo ambiental na escola. Utilizaram-se entrevistas reflexivas com nove professores, o que possibilitou a construção da proposta da mandala, a qual nos remete ao movimento da formaçáo do educador que valoriza o ser, o sentir e o agir, o olhar para suas potencialidades realizadas no seu mundo vivido, dialogando sobre suas práticas educativas e sociais.
\end{abstract}

Palavras-chave: Experiência vivida. Educação Ambiental. Formação Continuada.

\begin{abstract}
This article introduces a study developed from the experience lived throughout continuing education of teachers in Management of Education in Itajaí-SC (GERED). The aim was to reflect on the essential elements in continuing education which spread out the insertion of environmental education in schools. The research was carried out through thoughtful interviews with nine teachers, enabling the construction of the mandala, which leads to the movement of educator's development, consequently expressing values of being, feeling and acting, looking at one's potentials performed on their living world, dialoguing about their educational and social practice.
\end{abstract}

Keywords: Living experience. Environmental Education. Continuing Education.

1 Doutora e Mestre em Educação pela Universidade do Vale do Itajaí. Integrante grupo de Pesquisa Educação, Estudos, Ambientais e Sociedade (GEEAS). Técnica na Gerência de Educação, na Agência de Desenvolvimento Regional de Itajaí-SC. Secretaria de Estado do Desenvolvimento Regional - Itajaí (SC), Gerência de Educação. Rua Jorge Mattos, Centro, 88302130 - Itajaí-SC- Brasil. Telefone: (47) 33985993. E-mail: <mafraorsi@yahoo.com.br>.

2 Pós-Doutor em Educação Ambiental, Doutor em Engenharia de Produção - Mídia e Conhecimento; Mestre em Educação, Prof. do Programa de Pós-Graduação em Educação da Universidade do Vale do Itajaí. Universidade do Vale do Itajaí, Programa de Pós-Graduação Mestrado em Educação. Rua Uruguai, 458 - Bloco F7 - 4 andar - sala 10 Fazenda 88302202 - Itajaí-SC-Brasil - Caixa-postal: 360 Telefone: (47) 33417516 Ramal: 8005 Fax: (47) 33417822 URL da Homepage: <http://www.univali.br/ppge>. E-mail: $<$ afguerraea@gmail.com>.

R. Educ. Públ.

Cuiabá

v. 28

n. 67

p. $127-148$ jan./abr. 2019 


\section{Introdução}

Para discutir as questões ambientais na Educação, é necessário o educador ambiental ter, em mente, que estará abordando questóes que exigem mudanças de concepções e representações, transformações sociais, alterações de pensamento, articuladas com mudanças de hábitos, de atitudes e valores e da forma de agir do ser humano, consigo mesmo, na relação com o outro e com meio em que está inserido - local e global.

É uma tarefa nada fácil realizar essa transformação, porém acreditamos ser possível que ela ocorra. Não pretendemos ser ingênuos ao abordar o tema dessa forma, mas apontar o quanto essas questóes nos tem mobilizado na busca de orientaçóes e suportes que propiciem um alicerce objetivo para atuar na funçáo profissional de planejar e promover a formaçáo continuada na rede estadual de educaçáo de Santa Catarina, especificamente na Gerência Regional de Itajaí (GERED-Itajaí). Sabemos o quanto esse processo exige um conjunto de fatores e atores para poder ser trabalhado.

De acordo com a Proposta Curricular de Santa Catarina (PC/SC), de 1998, a Educação Ambiental (EA) é compreendida como um "processo educacional na gestão, no currículo, na formação continuada do docente/discente e comunidade" (SANTA CATARINA, 2014, p. 63).

Para dar sentido ao trabalho pedagógico do professor, as atividades em EA estão longe de se resumirem a vínculos com datas comemorativas, ou a campanhas e gincanas de coleta de resíduos, limpeza de rios e praias, necessárias, mas não suficientes. A intenção está em se promover práticas educativas bem mais conectadas às ações coletivas, visando à construção de valores socioambientais, por meio de estratégias e açóes que promovam a apreensão de conhecimentos e outros saberes ambientais e socioculturais, bem como ao desenvolvimento de atitudes, habilidades e competências válidas para propor soluções ou minimizar os problemas socioambientais encontrados nas suas comunidades - de forma local e planetária.

Sem dúvida, estamos diante de uma série de desafios, cujos conceitos se apresentam, constantemente, em processos de construção. Se avaliarmos o simples fato de a temática da Educação Ambiental ser inserida nos currículos de nossas instituiçóes de ensino, vamos perceber, ao longo da história, o quanto esse campo já percorreu para que essa ação se concretizasse. Porém, mesmo com tal avanço, uma série de obstáculos se apresentam para a apreensão dos conceitos do saber ambiental, assim como para o desenvolvimento de estratégias de ambientalização curricular, como exige o desafio apresentado pelas Diretrizes Curriculares 
Nacionais para a Educação Ambiental (DCNEA) (BRASIL, CNE-MEC, 2012, Artigo 14, inciso V), no sentido de que as instituiçóes de ensino, de todos os níveis, passem pela transição de se tornarem espaços educadores sustentáveis, "integrando proposta curricular, gestão democrática, edificaçóes, tornando-as referências de sustentabilidade socioambiental.” (p. 5).

Por outro lado, por interferência das diferentes mídias, as verdadeiras causas da problemática socioambiental, entre elas o consumismo, provocam uma série de conflitos, uma vez que individualizam as questóes, resumindo-as, quase sempre, a ações pontuais como, por exemplo, a reciclagem/coleta seletiva; e a dualidade entre desenvolvimento sustentável/sustentabilidade - trabalhados equivocadamente como sinônimos, de sorte que, tanto para o professor quanto para o educando, chegam informaçóes desencontradas e confusóes conceituais que aportam, nas nossas escolas, sem a devida crítica e aprofundamento, faltando, às vezes, espaços formativos para a compreensão dos contextos ideológicos, políticos, culturais que envolvem a problemática socioambiental.

Nesse aspecto, Guimarães (2004) aborda como essencial a ruptura com as "armadilhas paradigmáticas" como uma primeira aposta para a formação dos professores educadores ambientais. Ressalta a necessidade de uma abordagem crítica na EA, voltada para uma prática transformadora "calcada em novos paradigmas, condiçóes materiais, posturas ético-políticas, entre outros." (p. 48).

No entanto, a inserção da dimensão da EA ainda é algo relativamente recente nos currículos de nossas Instituiçóes de Educação Superior (IES), e como uma temática a ser trabalhada nas escolas da Educação Básica. Assim, vivemos um momento de muitas preocupaçóes, quando se torna urgente a necessidade da formação continuada de professores educadores ambientais. É importante lembrar o principal marco legal da política de EA, a Resolução n. ${ }^{\circ} 2$, de junho de 2012, do Conselho Nacional de Educação (CNE), que criou as DCNEA, atendendo a uma antiga reivindicação dos educadores ambientais brasileiros. No que diz respeito à formação, destaca-se, nesse contexto, o artigo 19:

Os órgãos normativos e executivos dos sistemas de ensino devem articular-se entre si e com as universidades e demais instituiçôes formadoras de profissionais da educação, para que os cursos e programas de formaçáo inicial e continuada de professores, gestores, coordenadores, especialistas e outros profissionais que atuam na Educação Básica e na Superior capacitem para o desenvolvimento didático-pedagógico da dimensão da Educação Ambiental na sua atuação escolar e acadêmica. (BRASIL, 2012, p. 7, grifos dos autores). 
Ainda sobre essa articulação, a referida Resolução complementa, no seu $\$ 2^{\circ}$, o compromisso de as instituiçôes de ensino instituírem políticas permanentes que incentivem os professores e lhes deem condiçóes concretas de formação continuada, para que se efetivem os princípios e se atinjam os objetivos da EA.

A função técnica exercida, desde 2003, na GERED, como responsável pelas questôes relacionadas à formação continuada em EA na regiáo e por todas as questóes que requerem articulação entre as escolas e a Gerência, nos oportunizou integrar várias açóes no campo ambiental, como, por exemplo, a responsabilidade de representação no Comitê da Bacia Hidrográfica do Rio Itajaí e em grupos de trabalho em EA regionais e municipais.

Nesse contexto, a oportunidade se ampliou a partir do momento em que, pela necessidade de planejar as formaçóes continuadas, iniciou-se uma relação com os pesquisadores do Grupo de Pesquisa Educação, Estudos Ambientais e Sociedade (GEEAS), da Universidade do Vale de Itajaí (UNIVALI). A partir desse movimento, houve a continuidade das açóes na GERED para desenvolver uma pesquisa referente à formaçáo continuada do Programa Vamos Cuidar do Brasil nas Escolas (PVCBE), desenvolvido na região da Associação dos Municípios da Regiáo da Foz do Rio Itajaí (AMFRI), em Santa Catarina, no Programa de Pós-Graduação em Educação (PPGE) da UNIVALI.

Desse contexto também emergiu a proposta de pesquisa de tese de investigar os resultados dos encontros de formação com os educadores da rede pública estadual, de 2010 e 2012, que contaram com a participação do GEEAS e do PPGE-Univali, em parceria com instituiçóes como a Fundação do Meio Ambiente de Itajaí (FAMAI) e a Defesa Civil Regional.

Os temas aventados nas referidas formaçóes foram definidos pelas questóes pertinentes à sustentabilidade, aos espaços educadores sustentáveis e à formação, nas escolas, da Comissáo de Meio Ambiente e Qualidade de Vida na Escola (COM-VIDA). A escolha das temáticas estava relacionada com os movimentos dos programas federais e com o desenvolvimento dos estudos realizados pelo grupo de pesquisa GEEAS. Assim, para esse grupo:

A preocupação com a questáo da sustentabilidade socioambiental local e global, suas causas, conflitos, possibilidades de enfrentamento e análise das políticas públicas em EA nos sistemas de ensino, constitui um dos eixos de pesquisa e intervenção nos processos de formação continuada em EA do Grupo de Pesquisa Educação, Estudos Ambientais e Sociedade (GEEAS). (GUERRA et al., 2010, p. 199). 
Esse diálogo acerca das temáticas ambientais é um campo de conflitos e tensôes. Da mesma forma, a produção textual sobre a política pública em EA é algo distante da sua efetiva prática pedagógica nas escolas, ou seja, os programas da política governamental envolvem o interesse e as ideologias de um determinado grupo, que nem sempre dialoga com a realidade do cháo da escola, inviabilizando, a sua prática. Como afirma Libâneo (2006, p. 2), "frequentemente se observa que as políticas educacionais não estão a serviço das escolas e dos professores, não decorrem das necessidades e demandas efetivas da realidade das escolas e dos alunos." Guimarães (2004), por sua vez, ao refletir sobre a crise da EA, refere que ela se insere na crise dos paradigmas da modernidade e "ainda não se faz presente, de forma significativa, no chão-daescola, o que ressalta a necessidade de investigar os caminhos para uma efetiva práxis da EA." (op. cit., p. 117).

Nesse cenário de crise, dar atenção à realidade da escola é fundamental, pois é nesse universo que se busca

[...] superar a rejeição a construção de conhecimento não acadêmico (pesquisa), passa pela aceitação da validade de outros conhecimentos, mesmo que cientificamente não validados. Isto faz parte da transição paradigmática proposta por uma educação crítica. (GUIMARÃES et al., 2010, p.7).

Coerente com a proposta de uma educação ambiental crítica e transformadora, a intenção do estudo apresentado neste artigo foi refletir sobre os elementos essenciais que, na formação continuada, ampliem a inserção da educação ambiental na escola pública, na busca de processos formativos em EA, os quais contemplem uma sólida fundamentação filosófica, teórica e metodológica, na expectativa de que a escola não fique refém apenas do discurso de reprodução da sociedade capitalista e da propaganda das mídias, mas sim que se estabeleça um movimento de ação-reflexão-ação em toda a comunidade escolar, propiciando-lhe ser geradora de transformaçóes que estabeleçam uma cultura de promoçáo da sustentabilidade em todas as suas dimensóes.

Assim, os fundamentos e os diálogos de saberes perpassam pelos sentidos, de sorte que os educadores se sintam mobilizados e se permitam um olhar diferenciado para as questóes da realidade socioambiental, mantendo-se como parte e como todo do processo educacional, percebendo-se um Ser em desenvolvimento, envolvido com o ambiente onde está inserido e constantemente na busca de alternativas para minimizar os problemas encontrados. 


\section{Caminho metodológico}

A abordagem da pesquisa foi qualitativa, com um olhar para o vivido, uma vez que expor a própria experiência de gestão das formaçóes continuadas em EA, propiciou "reexaminar com um olhar novo as imagens fielmente amadas, tão solidamente fixadas na minha memória que já não sei se estou a recordar ou imaginar quando as reencontro em meus devaneios." (BACHELARD, 2013, p. 2).

Nesse sentido, o foco do estudo envolveu três formaçóes com a temática da sustentabilidade e escolas sustentáveis, desenvolvidas nos anos de 2010 e 2012, contando com a participação de 86 educadores de 31 escolas estaduais. A seleçáo dos educadores ocorreu por meio da análise documental de projetos, atas e relatórios das formações continuadas em EA da Gerência de Educação GEREDItajaí-SC. Após esse levantamento, verificamos a atuação desses educadores e a existência de práticas de Educação Ambiental nas respectivas escolas. Dos 86 cursistas, 33 estavam atuando nas escolas.

Para a seleção dos cursistas utilizou-se, como critério, a verificação do envolvimento de cada um com as práticas curriculares em EA, selecionandose nove professores (as) educadores ambientais para fazerem parte da pesquisa, compartilhando suas vivências e experiências de vida e de formação com o vivido da pesquisadora. Após a confirmação dos professores, foi realizada uma entrevista reflexiva com roteiro semiestruturado, o qual permitiu nortear o encontro e o diálogo para que pudéssemos ir conversando e refletindo sobre as questóes que eram desencadeadas, de forma que, nas análises das narrativas, fosse possível refletir sobre a fala de cada entrevistado, a fim de que houvesse compreensão e reflexão de ambas as partes, como também aprimoramento da fidedignidade.

Nesse sentido, em cada entrevista procuramos estabelecer, com cada entrevistado, uma relação aberta e respeitosa, construída pelo diálogo e pela interação constante, uma conversa para reconhecer o que cada educador (a) considerava fundamental nas formaçôes de professores para a EA.

Para resguardar o anonimato de cada educador (a), e inspirados pelo mergulho total no contexto de leituras, buscas, experiências e deslumbramentos com a poética do devaneio de Gaston Bachelard e sua simbologia dos quatro elementos - terra, água, fogo e ar, optamos em estabelecer, para cada um (a), um codinome de uma pedra preciosa ${ }^{3}$, pois assim é que percebemos a vida e a prática docente dos educadores (as) entrevistados. Como uma joia rara, cada

3 Cada professor educador ambiental recebeu um codinome: Esmeralda, Pérola, Ametista, Rubi, Ônix, Safira, Ágata, Cristal e Coral. 
um deles se diferencia, por sua especificidade e brilho identificados, observando cuidadosamente e lapidando suas falas sobre o contexto em que desenvolviam sua ação docente nas escolas.

As nove entrevistas realizadas foram gravadas com aparelho de áudio e transcritas em arquivos do Microsoft Word ${ }^{\text {}}$, realizando-se, em seguida, o processo de expressar a fala em forma de narrativas, preservando o sentido e as expressóes dos entrevistados.

\section{O diálogo com os professores educadores ambientais sobre os processos de formação}

A formação docente é um processo que precisa integrar seus conteúdos e práticas à reconstrução de valores éticos e à valorização da práxis refletida, o que exige do educador transformação pessoal e reflexão sobre a própria imagem e a autoimagem profissional (ARROYO, 2000).

Imbernón (2009, p. 106) comenta que a profunda mudança ocorre "quando a formação passar de um processo de 'atualizaçáo' a partir de cima, para se transformar num espaço de reflexão, formação e inovação para que o professorado aprenda." Nesse tipo de formação elencada pelo autor, o formador tem o papel de contribuir para a reflexão do docente e não somente pela sua técnica, para ajudálo a "descobrir a teoria implícita na prática docente", ou seja, valorizar aquilo que somos e nos constituímos, saber ouvir e ser reconhecido: "A formação move-se sempre entre a dialética de aprender e desaprender." (op. cit., p. 106).

Nesse sentido, a formaçáo colaborativa de Imbernón (2009) ensina a aproveitar a prática docente como principal veículo para desvendar os obstáculos, promover mudanças, denunciar aquilo que oprime e também promover a esperança da mudança e da transformação.

A escuta de quem está no processo educativo é fundamental. Assim, uma das educadoras entrevistadas, Esmeralda, revelou que, para uma formaçáo continuada em EA, seria necessário um tempo e um espaço com mais autonomia no recinto da escola. Para ela: "O projeto só vai dar certo se todos os professores pararem. Paramos no início do ano para discutir PPP e calendário. Mas não há tempo na escola para realizar uma formação continuada. A escola não possui autonomia para realizar estas ações.” (Esmeralda).

Dar atençấo à sugestão dessa prática que persistiu nos relatos dos professores educadores é perceber que as mudanças devem ser realizadas pelo sistema macro de ensino. Um claro exemplo é que, geralmente, no início do ano letivo, o quadro dos educadores não está totalmente preenchido, dificultando a integração e o 
desenvolvimento pedagógico do grupo escolar. O pouco tempo disponível não permite um diálogo mais profundo para o estudo e a escolha da temática da formação, bem como a elaboração de uma proposta pedagógica coletiva. Que autonomia a escola possui nesse aspecto? De que tempo dispóe para planejar? São questóes reais traduzidas pela voz de Esmeralda, mas subjacentes aos depoimentos de todos os demais educadores.

Podemos ampliar essa questáo na perspectiva desse tempo/espaço de envolver uma formaçáo que reflita não somente o contexto vivido da escola, como nos apresenta Tristão (2003), quando afirma que: "o conhecimento hoje se processa para além do espaço/tempo da escola, as práticas educativas vêm absorvendo princípios, valores e produzindo sentidos sobre a Educaçáo Ambiental.” Segundo a autora, nos estabelecemos e nos relacionamos em vários contextos. $\mathrm{O}$ nosso vivido vai além do espaço escolar e está presente nas açóes vivenciadas no decorrer da vida. Por isso, a autora ainda se apoia na acepção de Spink (1998) sobre a perspectiva temporal dos três tempos presentes no contexto discursivo associados, aqui, aos contextos formadores, cujos tempos ela explica da seguinte forma:

Tempo curto refere-se às interaçóes do dia-a-dia, que têm por foco a funcionalidade das representaçóes e a dialogia - relaciono com o dia-a-dia da escola; tempo vivido, que abrange os processos de socializaçáo, o local de pertença de determinados grupos sociais, a ressignificação dos conteúdos históricos - articulo com as práticas pedagógicas e com a própria história pessoal no curso de vida das pessoas; tempo longo é o acúmulo de conhecimento produzindo a memória coletiva, o imaginário social, ou seja, uma concepção de natureza presente no passado e ressignificada no presente formaria os conteúdos sobre Educação Ambiental. No tempo longo, os repertórios disponíveis são moldados pelas contingências sociais, isto é, pelas redes de significados que constituem o espaço dos conhecimentos produzidos. (TRISTÃO, 2003 p. 25, grifos dos autores).

A explicação da autora sobre a importância dos espaços/tempos da EA nos remete, novamente, a Imbernón (2009), o qual, por sua vez, considera a existência de uma proposta permanente de formação, no sentido de superar alguns desses obstáculos dos espaços-tempos da escola, como destacados por Esmeralda. Para isso, seria necessário:

- a possibilidade de uma maior autonomia na formaçáo com a intervenção direta do professorado;

- partir dos projetos das escolas para que o professorado 
decida qual formação de que necessita para levar adiante o desenho, a colocaçáo em prática e a avaliaçáo do projeto. (IMBERNÓN, 2009, p. 39).

O autor citado se refere, assim, a "um processo formativo que possibilite o estudo da vida". Essa formação visualizada como processo precisa acontecer com base na reflexão do educador sobre sua própria prática, pois é nesse ambiente que emergem os obstáculos e aparecem tanto as dificuldades, como as potencialidades. Por isso, a importância de se constituir uma rede de saberes na qual os professores possam trocar experiências e aumentar a comunicaçáo entre os pares para pensar acerca de sua prática educativa e compartilhar acertos e erros.

Eu penso, deve ter oficinas, a prática, a troca de relatos de experiências com os professores, e inclusive a partir desse momento detectar as falhas as dificuldades no processo de ensino aprendizagem (Ametista). Sim acho bem importante este enfoque, é a relação da açáo/reflexão, a partir do momento que você vê um problema, discute e possibilita refletir para agir com a prática percebida (Pesquisadora). E eu já fiz essa reflexão no conselho escolar, reuni a APP e o Conselho Escolar. Comentei sobre o aprendi com relação ao agrotóxico. E dali foi retirado à ação deles próprios, pois normalmente aqui nas casas têm uma horta, um pomar, isso eu acho importante, trazer a comunidade e mostrar para a comunidade ou para alguns pais que participam junto do problema, que é o agrotóxico (Ametista).

Esse relato de Ametista expóe um elemento importante a ser trabalhado na formação, o qual vem persistindo nas orientações encaminhadas na pesquisa de Guerra (2001) e, nos últimos anos, ampliadas pelo grupo do GEEAS em suas pesquisas relacionadas ao processo de formaçáo em EA, no sentido de focar na metodologia adequada para o campo educacional, a qual envolva a dimensão do conteúdo escolar (conhecimentos, habilidades e competências, atitudes e valores) para inserir a dimensão ambiental no currículo. Segundo o autor, essa metodologia incorpora o saber fazer, o saber ser e o saber conviver (op. cit., p. 140, grifos dos autores). Tal proposta integra as seguintes dimensóes: cognitiva, metodológica, afetiva e ecosófica, explicadas da seguinte forma.

A dimensão cognitiva (conhecimentos e saberes); metodológica (habilidades e competências); afetiva (sensibilização para mudança e reflexáo sobre atitudes, valores éticos e estéticos, 
as relaçốes inter e intrapessoais; e a dimensáo ecosófica (GUATTARI, 1994), ou da ética e cidadania, intimamente relacionada à ação e reflexão sobre a ação (a práxis de Paulo Freire) individual e junto aos grupos sociais, envolvidos no processo de aprendizagem em EA [educação ambiental] (GUERRA; LIMA, 2004, p. 12, grifos dos autores).

É importante compreender que as referidas dimensões estão interligadas e, ao mesmo tempo, são interdependentes, em movimento constante para alcançar um processo efetivo de formação docente em Educação Ambiental. Para o autor, "todo esse processo gera um saber-poder de mudança que nos conduziria a novas formas de aprender e saber fazer, e também de saber ser e de conviver com os outros." (GUERRA, 2001, p. 147).

Hoje, os processos formativos de EA têm sua base epistemológica alicerçada em conhecimentos e no diálogo dos saberes ambientais que integram possibilidades de ser, sentir, conhecer e experienciar, permitindo um pensar e um agir dos professores educadores ambientais "por meio da sensibilização, informaçáo, contextualização e ação reflexivo-crítica" dos problemas socioambientais." (TAVARES; BRANDÁO; SCHMIDT, 2009, p. 193). Os autores apontam que uma EA baseada na ética e na estética dos sujeitos colabora para uma ação social responsável, ampliando o modo ver e atuar na vida.

Desse modo, e retomando também Tristão (2003), essa formação passa por tempos e espaços diferenciados, mas isso não ocorre de uma forma linear, uma vez que necessita de um olhar atento para sua constituição, com o cuidado de permitir momentos de construção coletiva entre os educadores e seu formador ou seu grupo de estudos. E partir, sempre, das práticas educativas, da sua experiência, conhecer a história dos envolvidos e buscar os elos entre ambas, compartilhar os problemas existentes e, coletivamente, buscar possíveis soluçóes por meio da construção de saberes. Além disso, essa formação é um movimento importante que mobiliza o individual para transformar os pensamentos, as atitudes e os valores com "aprofundamento no modo como enxergamos a Vida" (TAVARES; BRANDÁO; SCHMIDT, 2009, p. 181).

Nessa forma de pensar uma formação de EA, Pérola relatou a necessidade de cinco momentos: sensibilização; conhecimento teórico; vivência prática; plano de ação e avaliação.

No primeiro momento, sensibilização, sensibilizar os alunos, os professores que estariam fazendo parte dessa formação. Segundo, penso que eles têm que conhecer o histórico da educação ambiental, e perceber que nós fazemos parte do 
contexto, que nós não estamos fora desse contexto, que nós somos, é, parte. Terceiro, eu penso que uma saída de campo, com os colegas do curso, pra vivenciar um projeto, para vivenciar. Fazer parte do processo, vivenciar. Uma ação pode ser numa praia, num parque, dentro da escola, enfim, mas vivenciar e, em seguida, acho que nós temos que avaliar algum programa de educação ambiental, depois levantar literatura, procurar autores que respaldem o que a gente pensa, e depois desenvolver um plano de ação na escola, um projeto na escola, pra estar na pele, e realizar as atividades de educação ambiental na escola, e avaliar também o que a gente está fazendo lá. (Pérola).

Para Pérola, são vários os elementos que podem estar presentes na formação. A sensibilização já foi destacada por ela, desde o início de seus relatos, e a aponta como uma das potencialidades possibilitadas pela formaçáo continuada de 2010. Assim, prioriza seus primeiros passos na direção de estabelecer uma relação de confiança, humana e verdadeira com o educando, para que ele perceba o espaço onde vive e as relaçóes envolvidas entre eu, o outro e o ambiente. "Acreditamos que a relação do ser humano com o meio deve ser conquistada através da sensibilidade, da percepção e da reflexão crítica." (TAVARES; BRANDÁO; SCHMIDT, 2009, p. 185). Pérola sugere, ainda, que a formação seja exercida no grupo, envolvendo fundamentos teóricos, práticos, avaliaçáo e reflexão das açóes pactuadas pelo e no grupo.

Os autores enfatizam que há uma grande propagação da Educação Ambiental no processo educacional, porém essa ação educativa contém fragilidades na prática pedagógica. $\mathrm{Na}$ maioria das vezes, o professor preocupa-se com a problemática ambiental de seu entorno, discute e mobiliza, entretanto não consegue uma transformação da realidade.

Nossa prática como formadores em EA converge com as ideias dos autores e autoras até aqui mencionados, destacando-se a de Guimarães (2004), quando afirma que os professores, apesar de sensibilizados e mobilizados e de terem inserido a dimensão ambiental em suas práticas educativas, não conseguem ir além de uma proposta de educação conservadora ${ }^{4}$ que permita sair dos "questionamentos das práticas escolares dominantes" (p. 120). Assim,

4 "Esses professores foram ou estão sendo formados, em sua maioria, na mesma perspectiva conservadora de educação que reproduz a e se reproduz na armadilha paradigmática. Ou seja, dada uma compreensão de mundo moldada pela racionalidade, fazer diferente do caminho único prescrito por essa racionalidade, efetivando-se a hegemonia." (GUIMARÃES, 2004, p. 124). 
concordamos com o autor quando indica, no fazer pedagógico, um novo pensar voltado à "transformaçáo de um mundo ambientalmente sustentável" (GUIMARÁES, 2004, p. 120), o que nos remete, também, à necessidade de uma reflexão crítica como força propulsora “... é a ruptura radical com o colonialismo e a recusa igualmente radical ao neocolonialismo" (FREIRE, 1992, p. 91). Para essa ruptura com transformaçóes significativas, é necessária a intervenção do que Guimarães (2004, p.133) chama de "sinergia de um movimento em conjunto". Segundo ele, não adianta uma ação individual ou intervenções pontuais; a ação deve ser conjunta, pois é a força do coletivo que forma a sinergia, "uma resistência como uma contra correnteza" (p. 132).

Uma forma de resistência, de acordo com o autor, é a formação de dinamizadores de ambientes educativos (educador ambiental) que agem no processo de intervenção, motivados pela reflexão crítica das dinâmicas da realidade socioambiental. Para o educador ambiental ser esse dinamizador, é fundamental trabalhar uma liderança que permita transitar e movimentar-se no conjunto coletivo de resistência.

Esse educador ambiental, como liderança, precisa compreender o contexto da realidade socioambiental em que vai intervir. Sugere, o autor, que, inicialmente, se pode realizar o diagnóstico socioambiental conhecendo a realidade, suas condições, valores, hábitos, atitudes dominantes exercidas pelo grupo, para, depois disso, trabalhar os conflitos, problematizar e movimentar a comunidade para a construçáo da sustentabilidade socioambiental. Esse educador é um ser humano que precisa ser percebido em sua plenitude e ser valorizado, não somente como um ser que pensa, mas que também sente, vive em grupo e se relaciona um com outro e com o mundo, pois a "educação se dá na relação" (p. 143). Por isso, a importância de uma autoformação eclética, destacada pelo autor: transitar pelas ciências, pelas artes, pela filosofia e ser um interlocutor na articulação dos diferentes saberes.

A fala de Rubi nos traz elementos para compreender esse processo dialético de formação pela práxis:

Acho que tem que mostrar para os professores que dá para trabalhar e ver o resultado. Talvez trazer modelos que deram resultados no passado, que daria para implantar, para o professor ver que dá certo. Assim, não ficar só na parte teórica, partir para a prática... Precisamos de muita parceria. Poderiam vir estagiários da universidade na escola, para atender toda a escola, assim todos os professores poderiam atuar. Precisamos de empresas nos apoiando, antes a Petrobrás e a Malwee muito ajudavam nos trabalhos, hoje não conseguimos mais estas forças. (Rubi). 
Nesse sentido, Rubi visualizou uma formação a partir do que já se realizou, de uma práxis, de uma ação, sugerindo parcerias entre as secretarias de educação, universidades e empresas, visualizando e ampliando o processo formativo não apenas com essas questóes práticas ou modelos do passado. Temos o desafio de romper com a armadilha paradigmática para a construção de um ambiente educativo que propicie um movimento em conjunto, o qual visualize um trabalho de resistência contra atividades individuais ou açóes pontuais, sem a devida reflexáo a respeito das causas dos problemas socioambientais.

$R u b i$ apontou a parceria com a universidade e com a presença de estagiários no contexto escolar para promover diálogos, trocas de experiências e pesquisas que movimentem a escola. Essa parceria já foi destacada por Guerra e Orsi (2008), a partir dos estudos de Leme (2006, p. 41), como uma possibilidade de intercâmbio "principalmente na sistematização e divulgação dos saberes produzido a partir das experiências".

Por seu turno, Ônix também sugeriu uma formação entre as escolas com intercâmbios, além da iniciativa de instauração de uma política estadual de formação continuada.

Mas com os professores seria uma coisa diferente, fazer um intercâmbio das formaçóes que acontecem no início e do meio do ano entre as escolas, para comparar outras ideias, para fazer um encontro dos professores, não só das mesmas disciplinas, mas fazer um encontro. Para a formação em educação ambiental para os professores, como ela não é uma disciplina e nem um curso superior. Então, deveria talvez ser disponibilizado pelo governo estadual uma pós graduação em educação ambiental para todos os professores, principalmente os que não são das áreas de ciências biológicas e geografia, para aplicarem a EA na sua disciplina. (Ônix).

Ele abordou uma formação baseada na troca de experiências, como também uma possibilidade de permitir, ao educador, conhecer outros contextos, desde os problemas socioambientais, até os encantamentos pelas realidades vividas, uma ampliação dos aspectos geográficos, sociais, culturais e ambientais das escolas, salientando não se tratar de encontros por áreas, mas da reuniáo de todos os educadores, de forma a aumentar o diálogo e estreitar suas relaçóes para visualizarem as potencialidades e os entraves nas práticas pedagógicas. Em resumo, como salienta Imbernón (2009), criar estruturas de redes organizativas 
[...] que permitam um processo de comunicação entre os pares e intercâmbio de experiências para possibilitar a atualização em todos os campos de intervenção educativa e aumentar a comunicação entre o professorado para refletir sobre a prática educativa mediante a análise da realidade educacional, a leitura pausada, o intercâmbio de experiência, os sentimentos sobre o que acontece, a observação mútua, os relatos de vida profissional, os acertos e os erros... que possibilitam a compreensão, a interpretação e a intervenção sobre a prática. (op. cit., p. 40-41).

A mesma pedra preciosa também teve o cuidado e a intencionalidade de apontar a necessidade de formação continuada por meio de especializaçóes, pois a EA, recentemente, está nos currículos das IES, revelando a precariedade existente no acesso desse conhecimento. Por isso, é fundamental um investimento nas Políticas Públicas de EA, por meio dos programas para o fortalecimento e a institucionalização da EA, para a qual o processo de ambientalização pode ser um caminho.

Porém, mesmo que as açóes de formação e aperfeiçoamento docente tenham sido incorporadas à política nacional (como o caso do Programa Nacional de Formação de Educadores (as) Ambientais - ProFEA ${ }^{5}$ ) e estadual (Programa Estadual de EA - ProEEA), e aos cursos de formaçáo continuada oferecidos, infelizmente ainda não se tornou efetiva, o que coloca em questão as fragilidades presentes no sistema educacional, reforçando a tese de que somente a existência de boas leis e bons programas não garante a sua aplicabilidade e as transformaçóes que a Educação e a realidade exigem.

Assim, concluiu-se que sair do papel para a realidade e da teoria para a prática ainda é um desafio. Por isso, é fundamental pensar na formação permanente dos educadores aliada às políticas da carreira profissional, como salienta Imbernón (2009, p. 42-43):

A formação por si só consegue muito pouco se não estiver aliada a mudanças do contexto, da organização, de gestão e de relaçóes de poder entre os professores. O tão mencionado desenvolvimento profissional não recai na formação, mas em diversos componentes que se dão conjuntamente na prática de trabalho do ensino.

5 Ver Caderno do ProFEA, em <http://www.mma.gov.br/estruturas/educamb/_arquivos/dt_08.pdf>. Acesso em: 01 set. 2016. 
Safira, no seu relato, abordou a importância da avaliação como um processo que precisa estar presente nesse caminho.

Tem que fazer um encontro, tem que haver cobrança. A pessoa que estava encarregada de ir no curso tem que promover açóes. E assim fez tudo que tu for trabalhar, a questão da água, questão dos resíduos, seja lá o que for trabalhado, a pessoa que entenda do assunto, né, que saiba daquilo que tá falando, que possa passar pra gente segurança, e ó, é assim e assim que acontece, é por isso e por isso, pra gente ter uma noção. A gente não conhece, muitas vezes a gente é leigo no assunto, né. Sabe aquilo que os livros trazem e aquilo que tu procuras saber. E depois não ficar só ali, é um curso de uma semana, vou ficar só estudando gráfico e tal, não, agora a gente vai, entấo é a questão da água, então vamos fazer uma visita na SEMASA. Como é que isso funciona? Porque tem professor que não sabe por onde que passa, sabe que tem um filtro de decantação, de filtração disso e aquilo, mas não vivencia, não observa, não olha. Retornar para o curso, avaliar as açôes. (Safira).

Dessa forma, para Safira, há uma necessidade de cobrança com relação aos compromissos assumidos pelos professores que realizam as formaçóes. Faz-se necessário criar mecanismos para rever essa atitude, como nos aponta Imbernón (2009, p. 42), para o "desenvolvimento de uma cultura colaborativa no centro (análise, experiência e avaliação coletivamente) e de uma maior profissionalização docente através de projetos conjuntos."

Essa é uma cultura ainda ausente em nosso contexto escolar, o que gera conflitos e açóes isoladas de alguns professores educadores ambientais e nos faz refletir sobre a necessidade de repensar a formação continuada para formar formadores em EA. Isso pode ser construído na ótica apontada por Sauvé (2003), no documento Perspectivas curriculares para la formación de formadores en educación ambiental, um projeto de investigação-desenvolvimento colaborativo de cooperaçáo universitária internacional ${ }^{6}$, o qual apresenta um conjunto de fundamentos teóricos e curriculares para a Educação Ambiental, na perspectiva

6 Trata-se do Proyecto de Cooperación Universitaria Internacional Edamaz (Educación ambiental en Amazonia), outro marco do projeto ERE-Francophonie, que reuniu coparticipantes institucionais de cinco países da Francofonia, do Norte e do Sul (SAUVÉ, 2003, p. 2, tradução nossa). 
de uma formação de integração, investigação e intervenção que nos conduza a refletir e agir a respeito da problemática socioambiental, além do que temos e do que podemos melhorar no espaço educativo. Segundo a autora:

Encontra-se aqui uma preocupação em integrar a formaçáo, a pesquisa e a intervençáo. Trata-se de promover uma formação reflexiva na intervenção. A intervenção, por um lado, tanto é ambiental (um ato ou um projeto para o meio ambiente) e educativa (um processo de desenvolvimento pessoal e social). Por um lado, ela se inspira no campo teórico e prático da açáo ambiental e da açáo pedagógica; por outro lado, ela contribui para enriquecer estes últimos com o aporte dos participantes. (SAUVÉ, 2003, p. 11, tradução e grifos dos autores).

Esse programa possibilita o acompanhamento dos professores para esclarecer o conceito de Educação Ambiental, de acordo com atividades práticas para refletir as temáticas abordadas, em uma perspectiva crítica. Nesse sentido, os docentes exercitam sua argumentação com a sua própria concepção, nas intervençóes que fazem no decorrer da formação.

Para contemplar as atividades, o programa define alguns princípios da formaçáo continuada em EA, os quais, em nossa leitura, se aproximam do processo educativo e das metodologias empregadas nas formaçôes da GERED, inspiradas nos pressupostos epistemológicos, filosóficos e metodológicos estudados e aprofundados em nossa trajetória no grupo de pesquisa do GEEAS-Univali, bem como das contribuiçóes para a formaçáo de educadores ambientais dentro de uma perspectiva crítica.

Como procuramos demonstrar neste artigo, essa comunidade de aprendizagem (ORELLANA, 2002), formada nos processos desenvolvidos pela GERED-Itajaí, de 2010 a 2012, com o suporte das abordagens propostas por Guerra (2001), Tristão (2001), Guimarães (2004), Sauvé (2003) e Freire (1981-1986), direcionam e convergem para o planejamento de um processo de formação continuada em Educação Ambiental que se caracteriza pelo diálogo como referência para a abordagem das diferentes dimensóes do processo educativo em EA: cognitiva, metodológica e afetiva.

A partir do movimento exercitado nesta pesquisa, é que apresentamos na Figura 1 uma síntese dos elementos constituintes de um processo de formação continuada de professores educadores ambientais. A construção dessa síntese representa tanto os fundamentos filosóficos e epistemológicos que dimensionam as práticas em EA, e com os quais dialogamos na pesquisa, quanto o aprendizado dos conhecimentos, saberes, valores e experiências resultantes do diálogo realizado 
entre a pesquisadora e as pedras preciosas, participantes desta pesquisa.

Figura 1: Representação dos elementos constituintes de um processo de formação continuada em EA

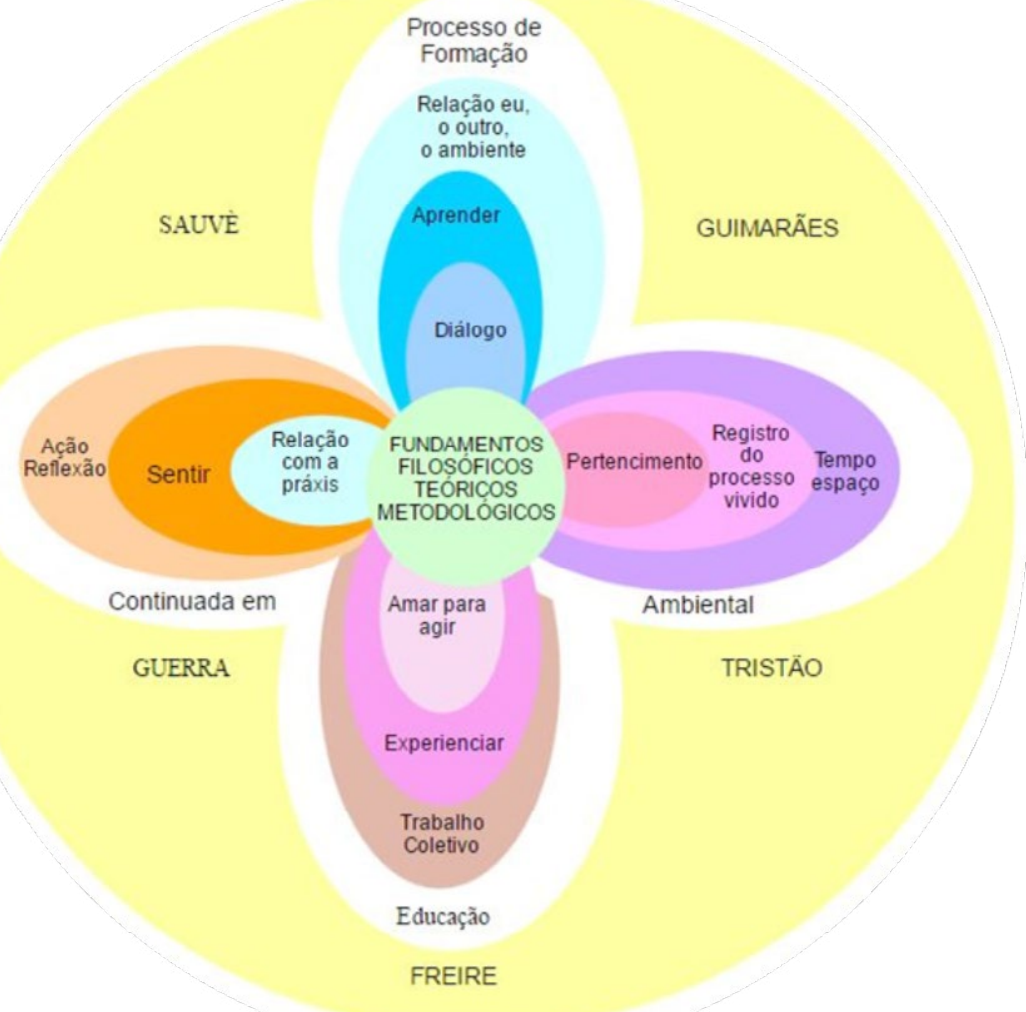

Fonte: (ORSI, 2016, p. 185)

A representação da Figura 1, sobre os elementos constituintes da formação do professor educador ambiental, pode ser compreendida como a síntese do caminhar ao longo deste estudo e da nossa formação como pesquisadores. As pétalas da mandala podem ser visualizadas em movimento circular, uma dança de ritmos e cores, em que cada pétala faz parte de um todo que se complementa.

A mandala incorpora elementos apresentados por Guerra (2001) - sobre a dimensão ambiental no currículo, permeada pela ênfase no estímulo à percepçáo e à educação em valores, bem como as proposiçóes de uma formaçáo do educador ambiental crítico, que possibilitam um movimento dialético de transformaçóes simultâneas do indivíduo e da sociedade, utilizando o diálogo como o instrumento principal para uma conexão com a realidade, que possibilite ação e reflexão, uma 
"práxis autêntica”, nas palavras de Freire (1981, p. 21).

Segundo Guimarães (2004), essa reflexão sobre a práxis consiste no caminho teórico-metodológico para compreender os sentidos, os limites, as carências e as rupturas, com o objetivo de "transformaçóes significativas" buscando amenizar os problemas socioambientais e promover um ambiente sustentável, cujos sentidos superem as fragilidades na prática pedagógica, ou seja, que a formação permita a construção de um fazer pedagógico direcionado à transformação da pessoa, do ambiente local e global, para tornar realidade o movimento de transição da escola para um espaço educador sustentável, a partir de um tempo/espaço impregnado de sentidos sustentáveis (TRISTÃO, 2003).

Nesse sentido, a mandala sinaliza, também, que a escola pode ser um ambiente de vida, de partilhar experiências em todos os contextos, possibilitando que a EA exerça seu papel e seu compromisso como uma dimensão essencial da Educação (SAUVÉ, 2005). Desse modo, se caracteriza por uma intensa inter-relação entre o eu o outro, a sociedade e o ambiente, em um movimento que transforma, reconhece e compreende os problemas socioambientais, buscando a formas de agir coletivamente em prol de uma sociedade sustentável e justa.

\section{Considerações Finais}

O percurso do presente estudo permitiu o exercício de percepção, leitura e construção de uma mandala de formação em EA que nos remete ao movimento que, em essência, é a formação por excelência do educador que valoriza o Ser, o sentir e o agir, não como gavetas desconectadas, mas como um movimento contínuo de ação-reflexão-ação, ou seja, de fazer-refazer caminhos, pensarrepensar outros modos de reencantar a Educaçáo.

A escolha pela representaçâo circular da mandala dialoga com todo o percurso da pesquisa realizada, abrindo a possibilidade de outros processos formativos possíveis, que pensem o ser como uma totalidade e a Educação Ambiental como uma escolha pelo cuidado com nossa Casa-Comum, que compartilhamos com outras tantas formas de vida ao universo que pertencemos.

Assim, propor uma proposta de formação continuada em EA, é permitirse Ser, olhar para seu interior e visualizar suas potencialidades realizadas no seu

7 Mauro Guimarães destaca que essas transformaçôes se referem à inserção de novas relaçôes na realidade, com a intencionalidade de ruptura das relações de dominação e exploração nas práticas individuais e coletivas, tornando-se uma causa de luta política, de vida e vivida (GUIMARÃES, palestra em 09 ago. 2016). 
mundo vivido e dialogar sobre suas práticas educativas e sociais.

O registro em forma de narrativa das pedras preciosas foi uma oportunidade de poder partilhar as suas e as nossas vivências, desenvolver um olhar reflexivo sobre si e sobre o outro, fazer uma releitura de sua própria vida vivida, além de poder apresentar ao outro suas experiências, seus acertos e também algumas dificuldades e obstáculos. Esse caminhar demonstrou que é possível romper com um sistema linear de processos formativos de recepçáo e transmissão de conhecimento isolado, e que é desejável a busca pelo trabalho coletivo, pela troca de saberes, mediado pelo diálogo, constituindo o fundamento de uma formação continuada que valoriza a diversidade epistemológica.

Esse movimento de perceber-se, sentir e registrar a sua práxis se intensifica com os estudos da realidade por meio de diagnósticos, visualizando os problemas ambientais como também as potencialidades locais, em um movimento coletivo para buscar alternativas para amenizar a crise ambiental. Por isso, entende-se a importância de contextualizar, conhecer e se apropriar de conceitos estruturantes do saber ambiental, por meio de atividades de intervenção que propiciem a ação/ reflexão na incorporação de práticas educativas que gerem mudanças individuais e coletivas que expressam a táo desejada transição das escolas para espaços educadores sustentáveis.

Assim, a fundamentação filosófica, teórica e metodológica delineia-se a partir do diálogo das necessidades, um movimento construído no processo que permita uma interação e uma construçáo coletiva para refinar o discurso/conhecimento/ metodologia, assim como resultado visualizar, a partir das potencialidades desse processo, práticas pedagógicas e sociais que transformem significativamente a sociedade de consumo.

Um fator importante nesse percurso é a maneira como vivenciamos o espaço/ tempo do aqui e agora, que revela que estarmos conectados com nosso sentir, com a nossa presença táo importante no mundo, no planeta, "é estar ancorado na realidade concreta” (SAUVÉ, 2016, p.291). Resulta, então, essa conexão de experienciar, de sentir, de não anestesiar nossa mente e o nosso corpo, de perceber nossos dilemas, as sensações e o prazer pela vida, a partir da interação de nosso movimento com o ambiente, a conexão com o cosmos. Essa conexão poderá ser desencadeada por atividades que mobilizem, tanto a cogniçáo, quanto os sentidos, como a música e a dança, que permitem uma extensão de percepção, não de um tempo linear, mas para sensação do aqui e agora da minha condição de Ser e estar nesse mundo vivido.

Pertencer a esse cosmos é religar a partir de sentimentos de amor e cuidado com a vida nosso planeta, fundamentais no processo formativo. De acordo com Oliveira, Pereira e Viana (2008), representam as açóes conosco mesmo, 
com o próximo e com a natureza, ou ainda, com as três esferas de interação do desenvolvimento pessoal e social (SAUVÉ, 2005), como um chamado para nossa atuação de responsabilidade. Enfim, estamos em relação eu, outro e o ambiente, por isso há de reconhecer a importância da ética dos valores, da nossa açáo comprometida nesse tripé de respeito e solidariedade com nossa Casa-Comum.

Com a metáfora da mandala, esperamos construir trajetos, navegar não solitária, mas coletivamente, num contínuo movimento de pensar o espaço da formaçáo como fonte, e o espaço escolar como aquele que se constrói com alegria, ousadia e, por vezes, com a necessidade de uma grande porção de poesia, arte, razão, valores, saberes, enfim, no processo vivido.

\section{Referências}

ARROYO, M. Ciclos de Desenvolvimento Humano e Formação de Educadores. Educaçáo \& Sociedade, ano XX, n. 68, p. 143-162, dez/1999.

BACHELARD, G. A Terra e os Devaneios da Vontade: Ensaio Sobre a Imaginação das Forças. 4. ed. Sáo Paulo: Martins Fontes, 2013.

BRASIL. Resolução no 2, de 15 de junho de 2012. Estabelece as Diretrizes Curriculares Nacionais para a Educação Ambiental. Diário Oficial [da] República Federativa do Brasil, Brasília, DF, 18 jun. 2012. Seção 1, 70 p.

FREIRE, P. A Pedagogia do Oprimido. Rio de Janeiro: Paz e Terra, 1981.

. Pedagogia da esperança. Rio de Janeiro: Paz e Terra, 1992.

GUERRA, A. F. S. Diário de bordo: navegando em um ambiente de aprendizagem cooperativa para educação ambiental. 2001, Florianópolis, 336 f. Tese (Doutorado em Engenharia de Produção) - Universidade Federal de Santa Catarina - UFSC.

SPINK, M. J. Práticas discursivas e produçáo de sentidos no cotidiano: aproximaçóes teóricas e metodológicas. São Paulo: Cortez, 1999.

; LIMA, M. B. A. Refletindo sobre a inserção da dimensão ambiental na formação docente. In: ZAKREZVSKI, S. B.; BARCELOS, V. Educaçáo Ambiental e compromisso social: Pensamentos e açóes. Erechim, RS: EdiFAPES, 2004, p. 41-61.

FIGUEIREDO, M. L. Sustentabilidade ou Desenvolvimento Sustentável? Da ambiguidade dos conceitos à prática em Educação Ambiental. In: GUERRA, A. F. S.; FIGUEIREDO, M. L. Sustentabilidades em diálogos. Itajaí: Univali, 2010, p. 191-212. 
; ORSI, R. F. M. Tendências, abordagens e caminhos trilhados no processo de formação continuada em educação ambiental. Revista Eletrônica do Mestrado em Educaçáo Ambiental, v. especial, p. 18-45, dez. 2008. Disponível em: < https://www.seer.furg.br/remea/article/view/3386/2032>. Acesso em: 17 jul. 2016.

GUIMARÁES, M. A formaçáo de educadores ambientais. Campinas: Papirus, 2004.

et al. A pesquisa na formação do Educador Ambiental. Ensino, Saúde e Ambiente, v. 3, p. 3, 2010.

IMBERNÓN, F. Formaçáo permanente do professorado: novas tendências. São Paulo: Cortez, 2009.

LEME, T. N. Os conhecimentos práticos dos professores: (re) abrindo caminhos para a educação ambiental na escola. São Paulo: Annablume, 2006.

LIBÂNEO, J. C. Sistema de ensino, escola, sala de aula: onde se produz a qualidade das aprendizagens. In: LOPES, A. C.; MACEDO, E. (Orgs.). Políticas de currículo em múltiplos contextos. São Paulo: Cortez, 2006, p.1-21.

ORSI, R. F. M. A formaçáo continuada do Programa Vamos Cuidar do Brasil com as escolas na regiáo da Amfri em Santa Catarina. 2008, Itajaí, 127 f. Dissertação (Mestrado em Educação), Universidade do Vale do Itajaí - UNIVAL.

. O movimento da formaçáo continuada em educaçáo ambiental: experiências vividas. 2016, 211 f. Tese. (Doutorado em Educação) - Universidade do Vale do Itajaí- UNIVALI.

SANTA CATARINA. Secretaria de Estado da Educação. Proposta Curricular: formação integral na Educação Básica, Secretaria de Estado da Educação, 2014, p. 63-66.

SAUVÉ, L. Perspectivas curriculares para la formación de formadores en educación ambiental. In: Foro Nacional sobre la incorporación de la perspectiva Ambiental en la Formación Tecnica Profesional, 1., San Luis Potosí, 9 a 13 jun. 2003. Anais..., San Luis Potosí, 2003.

. Educação Ambiental: possibilidades e limitaçóes. Revista Educaçáo e Pesquisa. São Paulo, v.31, n.2, p. 317-322, maio/ago. 2005.

TAVARES, C. M. S., BRANDAO, C. M. M., SCHMIDT, E. B. Estética e Educação Ambiental no paradigma da complexidade. Pesquisa em Educaçáo Ambiental, v. 4, n. 1, p. 177-193, 2009. 
TRISTÃO, M. Os sentidos da educaçáo ambiental nos contextos de formação de professores/as. In: REUNIÃO ANUAL DA ANPED, 24, Caxambu, 2001. Anais... Rio de Janeiro: Anped, 2001.

Contextos vividos e tecidos nos espaços/tempos da educaçáo ambiental.

Revista de Educaçáo Pública, UFMT, v. 12, n. 21, p. 25-41, 2003. 